\title{
Incineration, pyrolysis and gasification of electronic waste
}

\author{
Agnieszka Gurgul $^{1, *}$, Włodzimierz Szczepaniak ${ }^{1}$, and Monika Zabłocka-Malicka² \\ ${ }^{1}$ Wrocław University of Science and Technology, Faculty of Environmental Engineering, Wybrzeże \\ Wyspiańskiego 27, 50-370 Wrocław, Poland \\ ${ }^{2}$ Wrocław University of Science and Technology, Faculty of Chemistry, Wybrzeże \\ Wyspiańskiego 27, 50-370 Wrocław, Poland
}

\begin{abstract}
Three high temperature processes of the electronic waste processing: smelting/incineration, pyrolysis and gasification were shortly discussed. The most distinctive feature of electronic waste is complexity of components and their integration. This type of waste consists of polymeric materials and has high content of valuable metals that could be recovered. The purpose of thermal treatment of electronic waste is elimination of plastic components (especially epoxy resins) while leaving non-volatile mineral and metallic phases in more or less original forms. Additionally, the gaseous product of the process after cleaning may be used for energy recovery or as syngas.
\end{abstract}

\section{Electronic waste}

Rapid economic growth has resulted in an increase of production of electrical and electronic equipment (EEE) which is one of the fastest growing global manufacturing and it is still developing. Waste electric and electronic equipment (WEEE) is now considered as one of the fastest growing waste streams in EU, approximately $3-5 \%$ per year [1]. The amount of electric and electronic equipment put on market in 2013 in EU reached 8.1 million tonnes. In 2013, 3.6 million tonnes of WEEE were treated, of which 2.7 million tonnes were recovered.

The electric and electronic equipment includes a broad range of goods. Directive 2012/19/EU [2] defines 'electrical and electronic equipment' or 'EEE' as equipment which is dependent on electric current or electromagnetic fields in order to work properly. This type of waste includes large and small household appliances and IT equipments as computers, mobile phones, video and audio equipment. Furthermore, more appliances that were previously considered as electrical equipment as refrigerators are becoming 'electronic' through the addition of programmable microprocessors [3]. The development in production of electric and electronic waste is a cause of various environmental and economical problems. This type of waste contains diverse toxic substances that could be released to environment during landfilling or inappropriate processing. Therefore, this type of waste can pose considerable environmental and health risk if treated inadequately. On

* Corresponding author: agnieszka.gurgul@pwr.edu.pl 
the other hand, recycling of electronic waste is an important subject not only from the point of waste treatment but also from the recovery aspect of valuable materials. The recycling of WEEE offers opportunities of making secondary raw materials available on the market, especially valuable metals. In Table 1 it is presented concentration of metals in different electric and electronic equipment waste samples.

Table 1. Concentration of metals in different electronic scrap samples [4].

\begin{tabular}{|l|c|c|c|c|c|c|c|c|}
\hline \multirow{2}{*}{ Electronic waste } & \multicolumn{5}{|c|}{ wt.\% } & \multicolumn{3}{c|}{ ppm (wt.) } \\
\cline { 2 - 11 } & $\mathrm{Fe}$ & $\mathrm{Cu}$ & $\mathrm{Al}$ & $\mathrm{Pb}$ & $\mathrm{Ni}$ & $\mathrm{Ag}$ & $\mathrm{Au}$ & $\mathrm{Pd}$ \\
\hline TV board & 28 & 10 & 10 & 1.0 & 0.3 & 280 & 20 & 10 \\
\hline PC board & 7 & 20 & 5 & 1.5 & 1 & 1000 & 250 & 110 \\
\hline Mobile phone & 5 & 13 & 1 & 0.3 & 0.1 & 1380 & 350 & 210 \\
\hline Portable audio & 23 & 21 & 1 & 0.14 & 0.03 & 150 & 10 & 4 \\
\hline DVD player & 62 & 5 & 2 & 0.3 & 0.05 & 115 & 15 & 4 \\
\hline Calculator & 4 & 3 & 5 & 0.1 & 0.5 & 260 & 50 & 5 \\
\hline Printed circuit boards & 12 & 10 & 7 & 1.2 & 0.85 & 280 & 110 & - \\
\hline
\end{tabular}

Essential part of almost all of the electronic products are printed circuit boards (PCBs). Waste printed circuit boards (WPCBs) contain lots of valuable resources together with hazardous materials. This type of waste contains heavy metals (i.e., lead, cadmium) and hazardous substances that may pollute environment if they are not properly treated. However, a significant amount of valuable materials contained in WPCBs make them worth being recycled. Example value of some metals from PCB is presented in Table 2. The precious metals (gold, palladium, silver) make up more than $70 \%$ of the value of PCB that could be recovered.

Table 2. Composition and the intrinsic values of PCB metals [5].

\begin{tabular}{|c|c|c|c|c|}
\hline \multirow{2}{*}{ Component } & \multirow{2}{*}{ Wt.\% } & \multirow{2}{*}{ Value (f//kg) } & \multicolumn{2}{|c|}{ Intrinsic value of PCB } \\
\cline { 4 - 5 } & & & $(\mathbf{f} / \mathbf{k g}$ of PCB) & $\mathbf{( \% )}$ \\
\hline Gold & 0.025 & 14200.00 & 3.55 & 65.4 \\
\hline Palladium & 0.010 & 6200.00 & 0.62 & 11.4 \\
\hline Silver & 0.100 & 250.00 & 0.25 & 4.6 \\
\hline Copper & 16.0 & 3.30 & 0.53 & 9.7 \\
\hline Aluminium & 5.0 & 1.20 & 0.06 & 1.1 \\
\hline Iron & 5.0 & 0.10 & 0.01 & 0.1 \\
\hline Tin & 3.0 & 8.10 & 0.24 & 4.5 \\
\hline Lead & 2.0 & 1.30 & 0.03 & 0.5 \\
\hline Nickel & 1.0 & 13.20 & 0.13 & 2.4 \\
\hline Zinc & 1.0 & 1.20 & 0.01 & 0.2 \\
\hline
\end{tabular}

Due to high content of valuable metals in WPCBs, many researchers were using various methods to separate metals and nonmetals from this type of waste. Those methods include e.g. electrostatic separation, gravity separation, magnetic separation, hydrometallurgical and pyrometallurgical methods. Electronic waste represent a challenging problem mainly due to complexity of the material that consist of low value plastics and valuable metals that are integrated. Developing new clean technologies for recycling of WPCBs is a significant challenge. Processing of the waste should optimize recovery of materials and minimize final waste volume and process emissions. Thermal processes (incineration, pyrolysis and gasification) may be alternative solution for processing complex electronic waste. The purpose of thermal treatment of electronic waste is elimination of organic components (e.g. plastics) while leaving non-volatile mineral and metallic phases in more or less 
original forms that could be recovered. Additionally, the gaseous, liquid or solid products after cleaning may be used for energy recovery.

\section{Incineration of electronic waste}

Pyrometallurgical processes are currently the most important method of electronic waste processing. They are the final stage of the recovery chain, comprising in Europe approximately ten thousand collectors, one thousand dismantling installations and one hundred pre-processing units [6]. This stream of waste may be processed in two ways: smelting and incineration.

\subsection{Smelting}

There are only 3 metallurgical plants in Europe smelting and refining metal-bearing waste streams: UMICORE N.V., AURUBIS A.G. and BOLIDEN. The first two companies use ISASMELT $^{\mathrm{TM}}$ technology $[7,8]$, whereas Boliden uses Kaldo rotary furnace. In the Isasmelt ${ }^{\mathrm{TM}}$ technology, a vertical furnace was applied for smelting electronic waste and copper scrap mixture (plus necessary fluxes and recycled fly ashes). The furnace is fed from the top. The air, enriched in oxygen up to $90 \mathrm{vol} . \%$, is blown into the furnace also from the top. In the process, the melt is intensively mixed by the process gases - this mixing is essential for fast equilibration of the melt. Smelting is carried out at temperature of $1200^{\circ} \mathrm{C}$ (approximately.) Molten metal and slag are tapped from the furnace bottom. Precious metals are dissolved in molten copper. Further processing is typical for copper metallurgy: the copper is refined, electrolyzed and precious metals are recovered from anode slimes. According to Umicore [8], it is possible to smelt up to 1000 tons of material per day in the Isasmelt ${ }^{\mathrm{TM}}$ furnace.

\subsection{Incineration}

Contrary to smelting, formation of melts (in the first place oxide ones, as slags) is avoided during incineration. Such process is useful in the small scale processing of the electronic waste with high content of precious metals for further processing by hydrometallurgical routes. Typical rotary furnaces seem most useful in such processing, however stationary fluidized bed was also tested for electronic waste incineration in the laboratory scale[9]. Samples of the printed circuit board were heated for 3 minutes at $840-850^{\circ} \mathrm{C}$ and at 6.2 vol.\% of oxygen. Weight losses of the incinerated material were equal to approximately 21 wt.\%. Product of incineration was a brittle substance, suitable for chemical and mechanical processing. It was pulverized below $0.2 \mathrm{~mm}$ and was leached with sulfuric acid with concentrations from 30 to $95 \%$. With $95 \%$ concentration of sulfuric acid is possible to obtain almost complete leaching of copper (99.95\%) and precious metals (e.g. $97 \%$ for $\mathrm{Ag}$ ) [10].

\section{Pyrolysis of electronic waste}

Pyrolysis is a thermochemical decomposition of organic material at high temperature in the absence of oxygen. It involves changes of chemical composition and physical phase. In the pyrolysis process organic material, that is a part of electronic waste, is decomposed to molecular products that can be use e.g. as fuel. Pyrolysis of organic materials produces gas and liquid products and leaves a solid residue rich in carbon (char). Proportions of solid, 
liquid and gas yields depend on material that is pyrolyzed and process conditions. Zhou [11] conducted experiments of vacuum pyrolysis of waste printed circuit boards at $240^{\circ} \mathrm{C}$. Results of the pyrolysis experiments are presented in Table 3.

Table 3. Pyrolysis yields (wt.\%) of the two types of WPCBs [11].

\begin{tabular}{|c|c|c|c|c|c|c|c|c|}
\hline & \multicolumn{4}{|c|}{ Type -A } & \multicolumn{4}{c|}{ Type-B } \\
\cline { 2 - 9 } & Test 1 & Test 2 & Test 3 & Average & Test 1 & Test 2 & Test 3 & Average \\
\hline Solid yield & 68.7 & 70.1 & 69.7 & 69.5 & 76.1 & 75.6 & 75.4 & 75.7 \\
\hline Liquid yield & 28.2 & 27.3 & 27.9 & 27.8 & 19.5 & 20.3 & 20.1 & 20.0 \\
\hline Gas yield & 3.1 & 2.6 & 2.4 & 2.7 & 4.4 & 4.1 & 4.5 & 4.3 \\
\hline
\end{tabular}

The solid residue consisted of the glass fiber, electronic components, metals and other inorganic materials that could be recycled for further processing. Gaseous product of the process was rich in $\mathrm{CO}, \mathrm{CO}_{2}, \mathrm{CH}_{4}, \mathrm{H}_{2}$, etc. which makes this gas valuable for combustion. Energy recovered from combustion of the gas may be used in the process and therefore make pyrolysis a self-sustain (Fig.1).

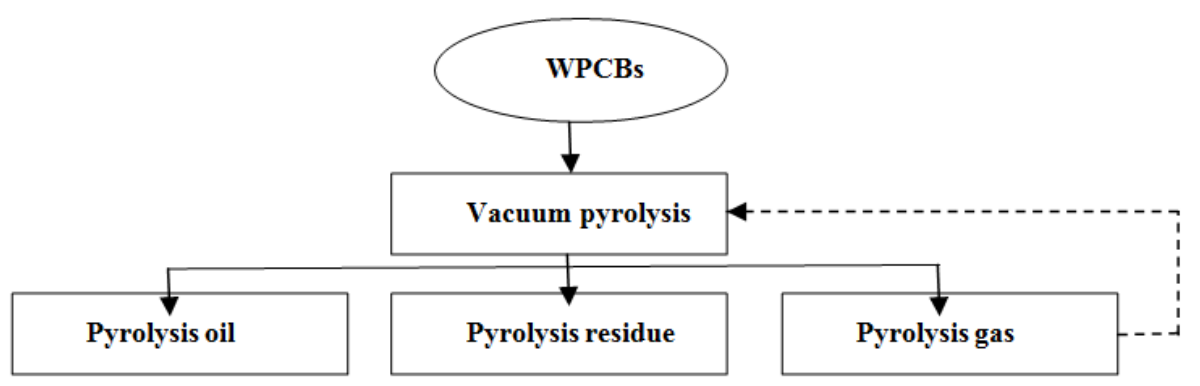

Fig. 1. Pyrolysis of WPCBs with recovery of syngas [10].

The residue of pyrolysis contained various metals (e.g., $\mathrm{Cu}, \mathrm{Fe}, \mathrm{Al}, \mathrm{Au}, \mathrm{Ag}, \mathrm{Pt}, \mathrm{Pd}$ etc.) that could be recovered in further processing. Content of those metals may vary depending on type of waste that is processed. Concentration of metals that were identified in the solid residue of various electronic waste pyrolysis is presented in Table 4.

Table 4. Concentration of metals in pyrolysis solids (wt.\%) [12].

\begin{tabular}{|c|c|c|c|c|c|c|c|c|c|c|}
\hline & $\mathbf{M g}$ & $\mathbf{A l}$ & $\mathbf{C a}$ & $\mathbf{M n}$ & $\mathbf{F e}$ & $\mathbf{N i}$ & $\mathbf{C u}$ & $\mathbf{Z n}$ & $\mathbf{S n}$ & $\mathbf{P b}$ \\
\hline $\begin{array}{c}\text { PE } \\
\text { wires }\end{array}$ & 0.6 & 72.4 & $<0.5$ & $<0.5$ & 0.9 & $<0.5$ & 16.4 & $<0.5$ & $<0.5$ & $<0.5$ \\
\hline $\begin{array}{c}\text { Table } \\
\text { phones }\end{array}$ & $<0.5$ & 4.7 & 1.0 & $<0.5$ & 4.7 & 0.6 & 18.0 & 1.6 & 0.6 & 1.0 \\
\hline $\begin{array}{c}\text { Mobile } \\
\text { phones }\end{array}$ & $<0.5$ & 0.6 & $<0.5$ & $<0.5$ & $<0.5$ & 0.8 & 12.4 & 2.8 & 0.8 & 0.6 \\
\hline $\begin{array}{c}\text { Circuit } \\
\text { boards }\end{array}$ & $<0.5$ & 8.7 & 1.8 & 0.6 & 3.9 & 0.5 & 36.4 & 3.5 & 4.6 & 3.8 \\
\hline
\end{tabular}

The metals may be separated and recovered in further processing. Each metallic element may be recovered in different physical and chemical processes, according to its characteristics. Pyrolysis can be considered as an alternative method of recycling electronic waste, because during the process organic content of waste is decomposed to product that can be used for energy recovery - the gas and to the solid combination of char and 
nonorganic materials, including metals, that can be recovered. In addition, pyrolysis significantly reduces the volume of the waste which is beneficial for further treatment. The combination of mechanical methods (separation, shredding), pyrolysis and chemical processing could increase efficiency of electronic waste recovery.

\section{Gasification of electronic waste}

Gasification seems to be an ambiguous concept in the literature and often is identified with pyrolysis (i.e. transformation of organic materials into gaseous species). However, we would like to define gasification as a process that requires an additional reagent, in contrast to pyrolysis for which only temperature determines generation of gaseous species. Therefore gasification, not pyrolysis, is the process that enables complete elimination of organic fractions to the gaseous phase at low oxygen potential of the system. Typical gasifying reagents are: steam, oxygen (air, oxygen enriched air) or carbon dioxide (much less). Considering steam gasification, there is an important difference between steam gasification and steam/oxygen/air processes - the former is endothermic (allothermal), whereas the later one is usually balanced as autothermic.

Gasification or pyrolysis are not cited in the literature as developed methods for metals recovery from electronic waste [13-15]. On the other hand, gasification was mentioned as accepted technology of municipal solid waste processing [16]. Recently, there were presented laboratory experiments of printed circuit boards gasification in molten carbonates by steam [17-19]. There is also a paper reporting an experiment of processing of plastics from printed circuit board to hydrogen by pyrolysis and steam conversion [20].

Taking into account total volume and composition of electronic wastes it seems, particularly from the Circular Economy point of view, that not gaseous product (syngas) but inorganic residue, especially metals, should be in the first place recovered. We believe, that direct steam gasification is a promising method of this recovery. It was demonstrated first time for the RAM waste, the data storage device comprising of FR-4 board and set of integrated circuits [21]. The original item, the crude product of gasification and some of materials which were the result of simple physical separation of the product are presented in Figure 2. Finally, 6 fractions were gathered: (from the integrated circuit) 1.1 - dies, 1.2 - ferromagnetic elements of leadframes, 1.3 - residue of encapsulation and (from PCB) 2.1 - copper foil, 2.2 - coarse metallic elements, 2.3 - fine fraction. Concentrations of some, typical for electronic waste metals in these fractions are presented in Figure 3. The differences between fractions and high level of precious metals are evident. There was also almost no char in the residue after gasification of organic fraction - epoxy resins.
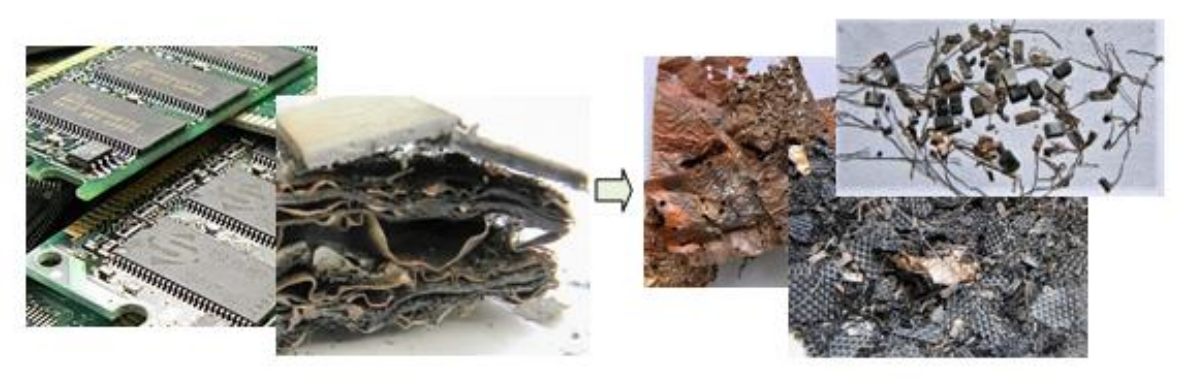

Fig. 2. Direct steam gasification of the RAM waste [15] (general illustration). 

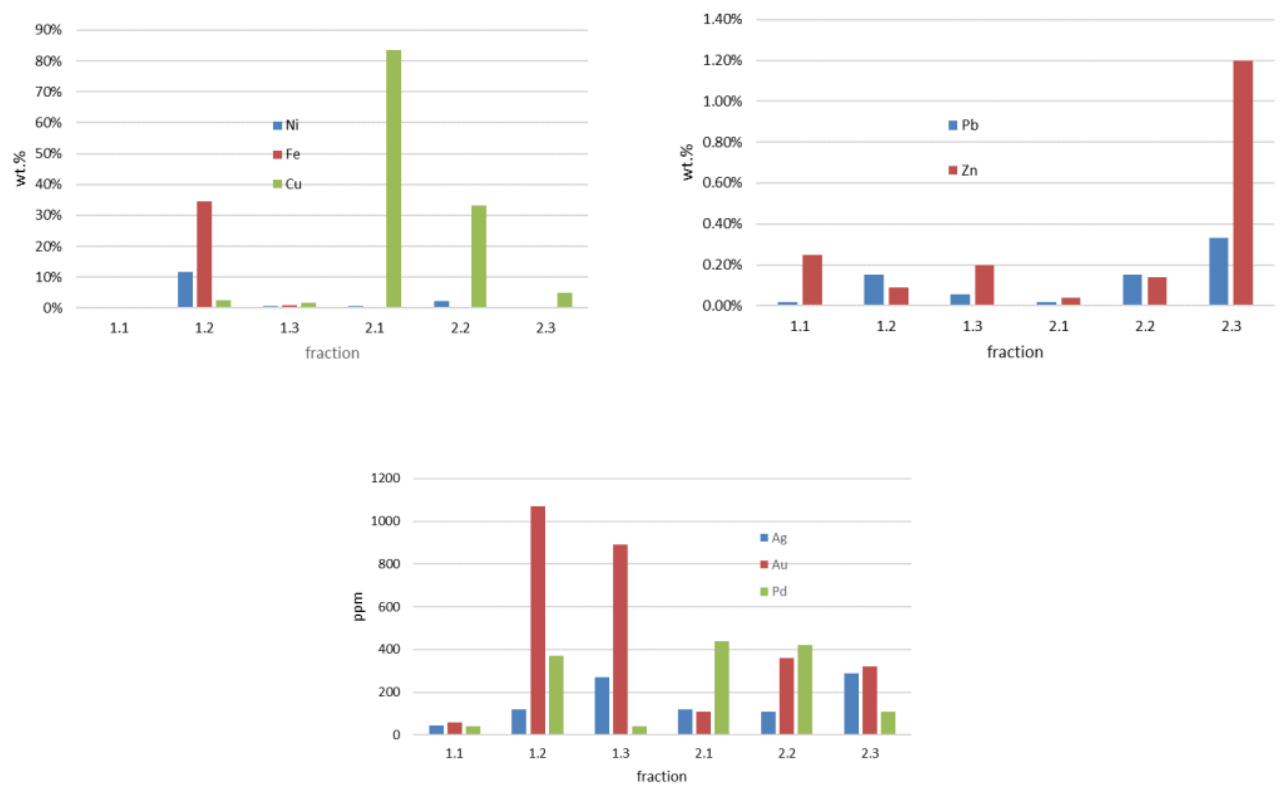

Fig. 3. Concentration of metals in the final product (fractions - description in the text) of steam gasification of the RAM waste [15].

Figure 4 is a good illustration of effectiveness of the steam gasification process for electronic waste. Gasification experiment was performed in a quartz reactor with samples of the raw FR-4 board at $860^{\circ} \mathrm{C}$ for few hours [A. Zielińska, Laboratory of HT Processes, $\mathrm{W} 7 / \mathrm{PWr}$. It may be noticed that the structure of the board was fully opened and the epoxy resin, which bonded fiber glass and copper layers, was completely removed.

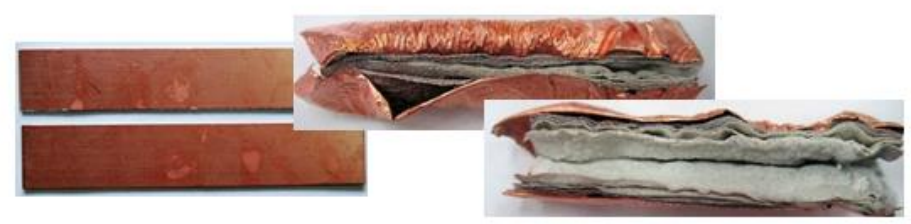

Fig. 4. Steam gasification of a raw FR-4 board [A. Zielińska, Laboratory of HT Processes, W7/PWr].

It should be kept in mind that allothermal steam gasification is useful not only in electronic waste processing - examples of gasification of the carton packaging, abrasive disc, bones, PCV-Cu wire and another electronic waste: PC ISA card, have been described in the accompanying paper [W. Szczepaniak, M. Zabłocka-Malicka, Steam gasification for waste valorization with energy recovery].

\section{Conclusion}

Increasing stream of electronic wastes is a valuable resource of metals, in the first place precious and copper, but also many others, ferrous and non-ferrous ones. Classical pyrometallurgical smelting processes are nowadays the major method of this waste processing. Generally, these processes are focused on precious metals and copper recovery. Organic materials (e.g. epoxy resins) are additional source of the heat; other components are collected in the slag or fly ash fractions. From this point of view, high concentration of 
chlorine or bromine is disadvantageous. However, there are undertaken efforts to develop alternative technologies, as incineration without smelting, pyrolysis or gasification. It seems, that the method of allothermal steam gasification is particularly interesting, because enables complete elimination of organic fractions without high oxygen potential of the gaseous phase, collecting volatile contaminants (including halides) in the aqueous condensate and production of $\mathrm{H}_{2}$-rich syngas. It should be noted that the air is not used in this process.

\section{Acknowledgments}

The work was financed by statutory activity subsidies from the Polish Ministry of Science and Higher Education for the Faculty of Environmental Engineering and Faculty of Chemistry of Wroclaw University of Science and Technology.

\section{References}

1. Eurostat (http://ec.europa.eu/eurostat/web/waste/key-waste-streams/weee)

2. Directive 2012/19/EU of The European Parliament and of the Council on waste electrical and electronic equipment (WEEE) (2012)

3. B.R. Babu, A.K. Parande, C.A. Basha, Waste Manage. Res. 27, 307-318 (2007)

4. J. Cui, L. Zhang, J. Hazard. Mater. 158, 228-256 (2008)

5. Y.J. Paryk, D.J. Fray, J. Hazard. Mater. 164, 1152-1158 (2009)

6. C. Hageluken, Exploring cross-border collaboration in R\&D, EIT-KIC-RM Seminar, September 14th, KU Leuven (2012)

7. G.R.F.A. Flores, S. Nikolic, P.J. Mackey, JOM 66, 823-832 (2014)

8. M. Caffarey, Recycling Electronic End of Life Materials, SERDC Recycling Summit (2012)

9. A. Woynarowska, J. Baron, S. Kandefer, W. Żukowski, Przem. Chem. 92, 997-1005 (2013)

10. A. Woynarowska, Termiczna utylizacja odpadów elektronicznych $w$ reaktorze fluidyzacyjnym (Politechnika Krakowska, Kraków, 2014)

11. Y. Zhou, K. Qiu, J. Hazard. Mater. 175, 823-828 (2010)

12. I. de Marco, B.M. Caballero, M.J. Chomon, M.F. Laresgoiti, A. Torres, G. Fernandez, S. Arnaiz, J. Anal. Appl. Pyrolysis 82, 2, 179-183 (2008)

13. L. Zhang, Z. Xu, J. Clean. Prod. 127, 19-36 (2016)

14. Y. Lu, Z. Xu, Resour. Conserv. Recy. 113, 28-39 (2016)

15. M. Kaya, Waste Manage. 57, 64-90 (2016)

16. U. Arena, Waste Manage. 32, 625-639 (2012)

17. S. Shang, K. Yoshikawa, H. Nakagome, T.Kamo, Appl. Energy 101, 815-821 (2013)

18. J.A. Salbidegoitia, E.G. Fuentes-Ordonez, M.P. Gonzalez-Marcos, J.R. Gonzalez-Velasco, T. Bhaskar, T. Kamo, Fuel Processing Technol. 133, 69-74 (2015)

19. S. Zhang, Y. Yu, Procedia Environ. Sci. 31, 903-910 (2016)

20. J.C. Acomb, M. Anas Nahil, P.T. Wiliams, J. Anal. Appl. Pyrolysis 103, 320-327 (2013)

21. P. Mońka, W. Szczepaniak, M. Zabłocka-Malicka, Czas. Tech. 1-Ch 108, 119-126 (2011) 